\title{
Pronounced effects of counterions on intramolecular electron transfer in $1^{\prime}, 1^{\prime \prime \prime}$-dinaphthylmethylbiferrocenium cation
}

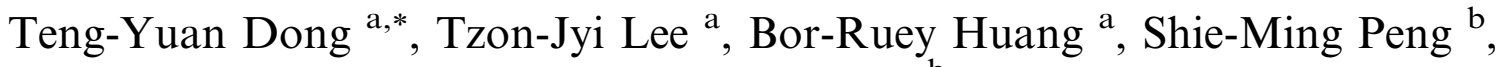 \\ Gene-Hsiang Lee ${ }^{b}$ \\ a Department of Chemistry, National Sun Yat-Sen University, Kaohsiung, Taiwan, ROC \\ ${ }^{\mathrm{b}}$ Department of Chemistry, National Taiwan University, Taipei, Taiwan, ROC
}

Received 22 August 2000; received in revised form 9 November 2000; accepted 17 November 2000

\begin{abstract}
The X-ray structure of $1^{\prime}, 1^{\prime \prime \prime}$-dinaphthylmethylbiferrocenium $\mathrm{BF}_{4}$ has been determined. The ${ }^{57} \mathrm{Fe}$ Mössbauer and EPR results of $1^{\prime}, 1^{\prime \prime \prime}$-dinaphthylmethylbiferrocenium $\mathrm{BF}_{4}$ and $\mathrm{PF}_{6}$ salts are also reported. The relatively minor perturbations caused by the counterions have pronounced effects on the rate of intramolecular electron transfer. (C) 2001 Elsevier Science B.V. All rights reserved.
\end{abstract}

Keywords: Mixed-valence 1', $1^{\prime \prime \prime}$-dinaphthylmethylbiferrocenium; Biferrocenium; Metallocene; Electron transfer

\section{Introduction}

The electron transfer between well-separated metal sites has already been discussed in chemical and biological systems [1-4]. In the cases of mixed-valence trinuclear iron acetates [5] and binuclear biferrocenium salts [6-23], it has been recognized that the variations in environmental conditions can dramatically affect the rate of intramolecular electron transfer. The series of mixed-valence biferrocenium salts (1a-e, Scheme 1), fulvalenide-bridged mixed-valence compounds with alkyl substituents, has been studied extensively in the solid state regarding the nature of the electronic structure in the ground state, various structural factors, lattice dynamics, and the cation-cation interactions. Compounds 1a-e give unusual temperature-dependent Mössbauer spectra. Hendrickson [5-7] suggested that the temperature dependence of the Mössbauer spectrum is due to the onset of lattice dynamics associated with the triiodide counterions and alkyl substituents. A very recent interesting finding is that there is a significant influence on the electron-transfer rate in the mixed-valence biferrocenium triiodide $\mathbf{2 a}$. We reported that $1^{\prime}, 1^{\prime \prime \prime}$-dinaphthylmethylbiferrocenium triiodide (2a) has two

\footnotetext{
${ }^{*}$ Corresponding author. Fax: +7-5253908.

E-mail address: dty@mail.nsysu.edu.tw (T.-Y. Dong).
}

distinct crystallographic phases and found that the electron-transfer rates are extremely sensitive to the changes in crystal lattice $[24,25]$. Two different crystalline morphologies ( $\mathrm{P} \overline{1}$ and $\mathrm{P} 2{ }_{1} / n$ phases) of $\mathbf{2 a}$ were found. The cation with space group ( $\mathrm{P} \overline{1}$ shows two doublets in the variable-temperature Mössbauer spectra at temperatures below $100 \mathrm{~K}$. An increase of temperature causes the two doublets to move together, resulting in an average-valence doublet at $130 \mathrm{~K}$, which is characteristic of a valence-detrapped cation in which the electron-transfer rate exceeds $-10^{8} \mathrm{~s}^{-1}$. On the other hand, the cation with $\mathrm{P} 2_{1} / n$ phase exhibits a Mössbauer spectrum characteristic of a valence-trapped cation at $300 \mathrm{~K}$. Obviously, the electron-transfer rate is quite sensitive to the environmental perturbations caused by different crystal packing arrangements.

The strategy of this study is the use of different counterions to show the close connection between mixed-valence state and the cation-anion interaction.

\section{Results and discussion}

\subsection{Molecular structure of $\mathbf{2 b}$}

Dark crystals in the monoclinic space group $\mathrm{P} 2{ }_{1} / c$ were obtained when a layer of hexane was allowed to 


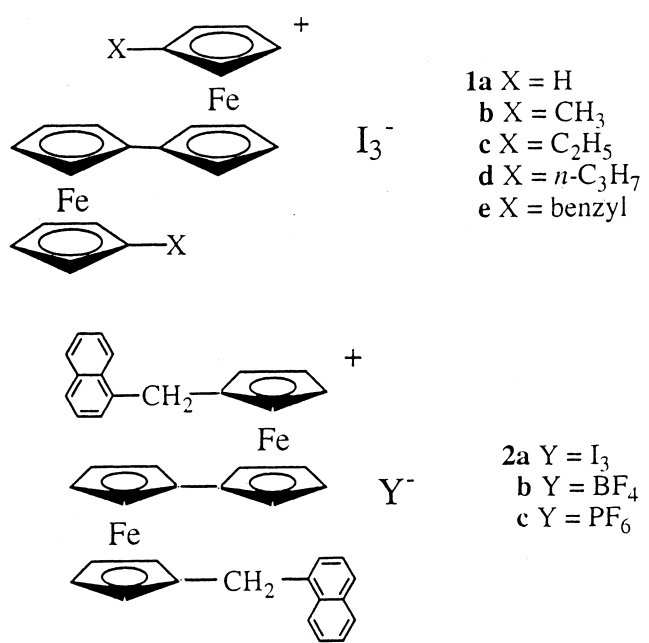

Scheme 1 .

slowly diffuse into $\mathrm{CH}_{2} \mathrm{Cl}_{2}$ solution of $\mathbf{2 b}$. As shown in Fig. 1, the two metallocene moieties in the cation are not equivalent. The average Fe1-C distance (2.072(5) $\AA$ ) and the Fe1-Cp distance $(1.692 \AA)$ indicate that this metallocene is in the $\mathrm{Fe}(\mathrm{III})$ oxidation state [26]. In contrast, the average $\mathrm{Fe} 2-\mathrm{C}$ distance $(2.052(5) \AA$ ) and the average $\mathrm{Fe} 2-\mathrm{Cp}$ distance $(1.660 \AA)$ indicate that this metallocene is in $\mathrm{Fe}(\mathrm{II})$ oxidation state [27]. The two $\mathrm{Cp}$
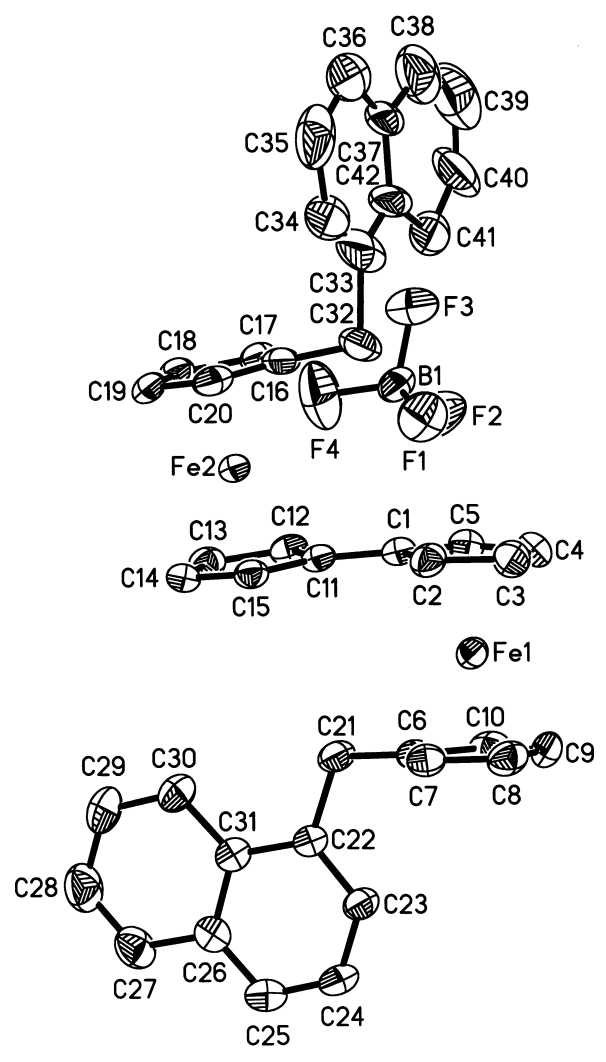

Fig. 1. Molecular view of $\mathbf{2 b}$ with 30\% thermal ellipsoids. Hydrogen atoms have been omitted for clarity. rings associated with $\mathrm{Fe} 1$ and $\mathrm{Fe} 2$ are not parallel, and the dihedral angles are $2.86^{\circ}$ and $3.52^{\circ}$, respectively. Furthermore, the two $\mathrm{Cp}$ rings associated with $\mathrm{Fel}$ and $\mathrm{Fe} 2$ are not eclipsed but are rotated relative to one another by $12.24^{\circ}$ and $3.36^{\circ}$. It is important to find the two metallocene units in $\mathbf{2 b}$ are twisted relative to each other. The two $\mathrm{Cp}$ rings in the fulvalenide bridge are not coplanar, and the dihedral angle between the $\mathrm{Cp}$ rings of the fulvalenide ligand is $7.83^{\circ}$. We believe that the degree of coplanarity between the two $\mathrm{Cp}$ rings in the fulvalenide bridge plays an important role in determining the magnitude of the electron-transfer rate.

\section{2. ${ }^{57} \mathrm{Fe}$ Mössbauer characteristics}

We examined microcrystalline samples of $\mathbf{2 b}$ and $\mathbf{2 c}$, formed by adding an ether solution of $0.1 \mathrm{M} \mathrm{HBF}_{4}$ or $\mathrm{HPF}_{6}$ to a benzene solution of neutral biferrocene and stoichiometric amount of $p$-benzoquinone. The variabletemperature ${ }^{57} \mathrm{Fe}$ Mössbauer spectra are shown in Fig. 2.

(a)
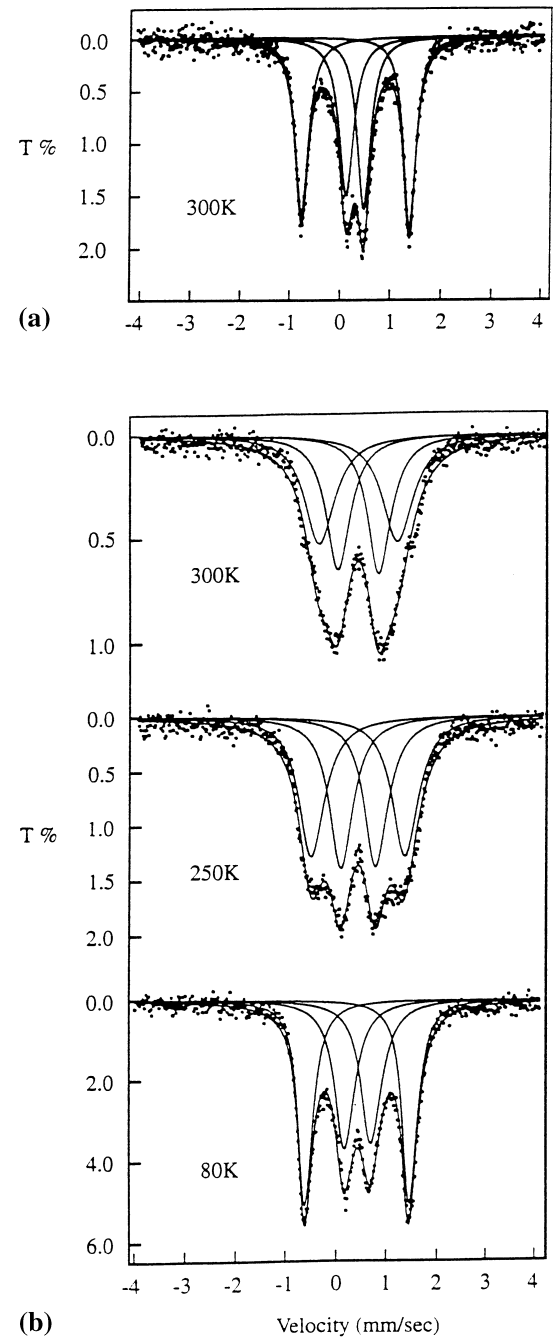

Fig. 2. Variable-temperature ${ }^{57} \mathrm{Fe}$ Mössbauer spectra of: (a) $\mathbf{2 b}$; (b) $\mathbf{2 c}$. 
The various absorption peaks were fitted to the Lorentzian lines. The prominent features in the $80 \mathrm{~K}$ Mössbauer spectra of $\mathbf{2 b}$ and $\mathbf{2 c}$ are two doublets, one with a $\Delta E_{Q} \cong 2.0 \mathrm{~mm} \mathrm{~s}^{-1}$ (Fe(II) metallocene) and the other with a $\Delta E_{Q} \cong 0.5 \mathrm{~mm} \mathrm{~s}^{-1}$ (Fe(III) metallocene). Both doublets were fitted to have the same area. This pattern of two doublets is what is expected for a mixedvalence biferrocenium cation which is valence trapped on the Mössbauer time-scale. In the case of $\mathbf{2} \mathbf{b}$, the two doublets do not move together as the temperature of the sample is increased to $300 \mathrm{~K}$ (see Fig. 2(a)). We believe that the localized electronic structure of $\mathbf{2} \mathbf{b}$ is mainly due to the noncoplanarity of the two $\mathrm{Cp}$ rings in the fulvalenide bridge. On the other hand, the sample of 2c exhibits an interesting Mössbauer behavior. As increase of temperature causes the two doublets to move together, $\Delta E_{Q}=1.550$ and $0.813 \mathrm{~mm} \mathrm{~s}^{-1}$ at $300 \mathrm{~K}$. Obviously, the intramolecular electron transfer is quite sensitive to the environmental perturbations caused by different counterions.

\subsection{Electron paramagnetic resonance}

X-band EPR spectra were run for the samples of $\mathbf{2 b}$ and $\mathbf{2 c}$ at 77 and $300 \mathrm{~K}$. The $77 \mathrm{~K}$ spectra of $\mathbf{2 b}$ and $\mathbf{2 c}$ are clearly axial-type spectra, and the $g$ values evaluated from these spectra and other related EPR spectra are collected in Table 1 . In the case of $\mathbf{2 c}$, the value of $g$ tensor anisotropy $(\Delta g)$ is considerably reduced. It appears that there is a correlation between the values of ( $\Delta g$ and $\Delta \Delta E_{Q}$ : the smaller $\Delta g$ value, the smaller $\Delta \Delta E_{Q}$ value (or the faster the electron transfer). This is a reflection of an admixture of the Fe(II) and Fe(III) electronic configurations.

\section{Comments}

We demonstrate that relatively minor perturbations caused by the counterions have pronounced effects on the electronic structure and the rate of intramolecular electron transfer. The dependence of the crystallinity of sample on the electronic structure and the possibility of various kinds of conformational arrangements caused by different counterions are also underway.

\section{Experimental}

\subsection{General information}

All manipulations involving air-sensitive materials were carried out by using standard Schlenk techniques under an atmosphere of $\mathrm{N}_{2}$. Chromatography was performed on neutral alumina (Merck, activity II). Sample of $1^{\prime}, 1^{\prime \prime \prime}$-dinaphthylmethylbiferrocene was prepared according to the literature procedure [25].

\subsection{Mixed-valence compounds $\mathbf{2 b}$ and $\mathbf{2 c}$}

Microcrystalline sample of $\mathbf{2}$ was prepared by adding an ether solution of $0.1 \mathrm{M} \mathrm{HBF}_{4}$ or $\mathrm{HPF}_{6}$ to a benzene solution of $1^{\prime}, 1^{\prime \prime \prime}$-dinaphthylmethylbiferrocene containing a stoichiometric amount of $p$-benzoquinone. The resulting dark crystals were filtered and washed repeatedly with benzene/ether (3:1). Recrystallization was carried out from $\mathrm{CH}_{2} \mathrm{Cl}_{2}$ /hexane as solvent. Anal. Calcd. for $\mathbf{2 b}\left(\mathrm{C}_{42} \mathrm{H}_{34} \mathrm{BF}_{4} \mathrm{Fe}_{2}\right)$ : C, 68.43; H, 4.65. Found: C, 68.45; H, 4.64. Anal. Calcd. for $2 \mathbf{c}\left(\mathrm{C}_{42} \mathrm{H}_{34} \mathrm{~F}_{6} \mathrm{Fe}_{2} \mathrm{P}\right)$ : C, 63.41; H, 4.31. Found: C, 63.41; H, 4.42 .

Table 1

EPR data of 2 and other related compounds

\begin{tabular}{|c|c|c|c|c|}
\hline Compound $^{\mathrm{a}}$ & $\mathrm{T} / \mathrm{K}$ & $g_{\|}$ & $g_{\perp}$ & $\Delta g^{\mathrm{b}}$ \\
\hline Biferrocenium $\mathrm{I}_{3}{ }^{\mathrm{c}}$ & 4.2 & 3.58 & 1.72 & 1.86 \\
\hline $1^{\prime}, 1^{\prime \prime \prime}$-dibutylbiferrocenium $\mathrm{I}_{3}{ }^{\mathrm{c}}$ & 4.2 & 2.98 & 1.92 & 1.06 \\
\hline \multirow[t]{2}{*}{$1^{\prime}, 1^{\prime \prime \prime}$-dibenzylbiferrocenium $\mathrm{I}_{3}{ }^{\mathrm{d}}$} & 4.2 & 3.02 & 2.01 & 1.07 \\
\hline & & & 1.89 & \\
\hline \multirow[t]{2}{*}{$1^{\prime}, 1^{\prime \prime \prime}$-diiodobiferrocenium $\mathrm{I}_{3}{ }^{\mathrm{e}}$} & 4.2 & 2.75 & 2.01 & 0.76 \\
\hline & & & 1.97 & \\
\hline $2 a^{f}$ & 77 & 3.16 & 1.91 & 1.25 \\
\hline \multirow[t]{2}{*}{$2 \mathrm{a}^{\mathrm{g}}$} & 77 & 3.67 & 2.01 & 1.66 \\
\hline & & 2.85 & 1.79 & 1.06 \\
\hline $2 b^{h}$ & 77 & 3.35 & 1.85 & 1.50 \\
\hline $2 \mathrm{c}^{\mathrm{h}}$ & 77 & 3.25 & 1.98 & 1.27 \\
\hline
\end{tabular}

${ }^{\text {a }}$ Powder samples.

${ }^{\mathrm{b}} \Delta g=g_{\|}-g_{\perp}$.

${ }^{\mathrm{c}}$ From Ref. [6].

${ }^{\mathrm{d}}$ From Ref. [28].

${ }^{\mathrm{e}}$ From Ref. [7].

${ }^{\mathrm{f}}$ With P1̄ phase.

${ }^{\mathrm{g}}$ With $\mathrm{P} 2{ }_{1} / n$ phase.

${ }^{\mathrm{h}}$ This work. 


\section{Supplementary material}

Tables of atomic, positional and thermal parameters, bond angles and distances. Crystallographic data for the structural analysis has been deposited with Cambridge Crystallographic Data Centre, CCDC 151980 for $2 \mathbf{b}$. Copies of this information maybe obtained free of charge from: The Director, CCDC, 12 Union Road, Cambridge, CB2 1EZ, UK (Fax: +44-1223-336033; email: deposit@ccdc.cam.ac.uk or www:http://www. ccdc.cam.ac.uk).

\section{Acknowledgements}

Acknowledgments are made to the National Science Council (NSC89-2113-M-110-003), Taiwan, ROC, and Department of Chemistry at Sun Yat-Sen University.

\section{References}

[1] P. Day, Int. Rev. Phys. Chem. 1 (1981) 149.

[2] D. Brown, Mixed-Valence Compounds, Theory and Applications in Chemistry, Phyiscs, Geology and Biology, Reidel, Boston, MA, 1980.

[3] C. Creutz, Prog. Inorg. Chem. 30 (1983) 1.

[4] D.E. Richardson, H. Taube, Coord. Chem. Rev. 60 (1984) 107.

[5] D.N. Hendrickson, S.M. Oh, T.-Y. Dong, T. Kambara, M.J. Cohn, M.F. Moore, Comments Inorg. Chem. 4 (1985) 329.

[6] T.-Y. Dong, D.N. Hendrickson, K. Iwai, M.J. Cohn, S.J. Geib, A.L. Rheingold, H. Sano, I. Motoyama, S. Nakashima, J. Am. Chem. Soc. 107 (1985) 7996.

[7] T.-Y. Dong, D.N. Hendrickson, C.G. Pierpont, M.F. Moore, J. Am. Chem. Soc. 108 (1986) 963.

[8] S. Iijima, R. Saida, I. Motoyama, H. Sano, Bull. Chem. Soc. Jpn. 54 (1981) 1375.

[9] [a] S. Nakashima, M. Katada, I. Motoyama, H. Sano, Bull. Chem. Soc. Jpn. 60 (1987) 2253;

[b] S. Nakashima, M. Katada, I. Motoyama, H. Sano, Bull. Chem. Soc. Jpn. 59 (1986) 2923; [c] S. Nakashima, Y. Masuda, I. Motoyama, H. Sano, Bull. Chem. Soc. Jpn. 60 (1987) 1673;

[d] S. Nakashima, T. Oka, T. Okuda, M. Watanabe, Inorg. Chem. 38 (1999) 4005;

[e] S. Nakashima, S. Nakazaki, H. Sakai, M. Watanabe, I. Motoyama, M. Sato, Inorg. Chem. 37 (1998) 1959.

[10] M. Kai, M. Katada, H. Sano, Chem. Lett. (1988) 1523.

[11] T.-Y. Dong, C.C. Schei, T.L. Hsu, S.L. Lee, S.J. Li, Inorg. Chem. 30 (1991) 2457.

[12] T.-Y. Dong, C.Y. Chou, J. Chem. Soc., Chem. Commun. (1990) 1332.

[13] T.-Y. Dong, C.C. Schei, M.Y. Hwang, T.Y. Lee, S.K. Yeh, Y.S Wen, Organometallics 11 (1992) 573.

[14] R.J. Webb, S.J. Geib, D.L. Staley, A.L. Rheingold, D.N. Hendrickson, J. Am. Chem. Soc. 112 (1990) 5031.

[15] R.J. Webb, A.L. Rheingold, S.J. Geib, D.L. Staley, D.N. Hendrickson, Angew. Chem., Int. Ed. Engl. 28 (1989) 1388.

[16] T.-Y. Dong, T. Kambara, D.N. Hendrickson, J. Am. Chem. Soc. 108 (1986) 5857.

[17] T.-Y. Dong, T. Kambara, D.N. Hendrickson, J. Am. Chem. Soc. 108 (1986) 4423.

[18] H.G. Jang, S.J. Geib, Y. Kaneko, M. Nakano, M. Sorai, A.L. Rheingold, B. Montez, D.N. Hendrickson, J. Am. Chem. Soc. 111 (1989) 173.

[19] Y. Kaneko, M. Nakano, M. Sorai, H.G. Jang, D.N. Hendrickson, J. Am. Chem. Soc. 28 (1989) 1067.

[20] T.-Y. Dong, T.Y. Lee, H.M. Lin, J. Organomet. Chem. 427 (1992) 101

[21] T.-Y. Dong, C.K. Chang, C.H. Huang, Y.S. Wen, S.L. Lee, J.A. Chen, W.Y. Yeh, A. Yeh, J. Chem. Soc., Chem. Commun. (1992) 526.

[22] T.-Y. Dong, C.H. Huang, C.K. Chang, Y.S. Wen, S.L. Lee, J.A. Chen, W.Y. Yeh, A. Yeh, J. Am. Chem. Soc. 115 (1993) 6357.

[23] T.-Y. Dong, S.H. Lee, C.K. Chang, H.M. Lin, K.J. Lin, Organometallics 16 (1997) 2773.

[24] [a] T.-Y. Dong, X.Q. Lai, K.J. Lin, Angew. Chem., Int. Ed. Engl. 36 (1997) 2002;

[b] A. Hori, H. Sakai, M. Watanebe, I. Motoyama, J. Organomet. Chem. 542 (1997) 271.

[25] T.-Y. Dong, P.H. Ho, X.Q. Lai, Z.W. Lin, K.J. Lin, Organometallics 19 (2000) 1096.

[26] N.J. Mammano, A. Zalkin, A. Landers, A.L. Rheingold, Inorg. Chem. 16 (1977) 297.

[27] P. Seiler, J.D. Dunitz, Acta Crystallogr. B 35 (1979) 1068.

[28] R.J. Webb, T.-Y. Dong, C.G. Pierpont, S.R. Boone, R.K. Chadha, D.N. Hendrickson, J. Am. Chem. Soc. 113 (1991) 4806. 